\title{
Welfare Implications of Sunspot Fluctuations
}

\author{
Sergey Slobodyan* \\ CERGE-EI, Charles University \\ Politických vězñu 7, 11121 Praha 1, \\ Czech Republic
}

\begin{abstract}
The usual conclusion in the literature is that sunspots reduce welfare because of the agents' risk aversion. However, if sunspots can lead to escape from an inferior steady state (poverty trap), this conclusion does not necessarily hold. Escaping trajectories can have much higher welfare than those remaining in the poverty trap. The ex-post welfare effect can be positive for initial conditions such that the probability of escape is sufficiently close to one. Numerical simulations of the model support this conjecture.

The distance from the poverty trap boundary to the initial condition point is of critical importance where the escape is concerned. I consider a model in which government has an influence on the exact location of the boundary. Implementing a policy that moves the boundary to the initial condition point greatly increases both the probability of escape and the expected welfare gain.
\end{abstract}

\begin{abstract}
Abstrakt
Ekonomické koncepty popsané v literatuře obvykle tvrdí, že tzv. „sunspoty“ snižují bohatství protože hráči jsou aversní vůči riziku. To však nemusí platit, pokud sunspoty vedou $\mathrm{k}$ úniku z inferiorního stacionárního stavu (pasti chudoby). Únikové trajektorie mohou vést $\mathrm{k}$ mnohem vyššímu bohatství než trajektorie pasti chudoby. Ex post vliv na bohatství může být značný pro počáteční podmínky, při kterých se pravděpodobnost úniku blíží jedné. Numerické simulace modelu toto tvrzení potvrzují.

Vzdálenost mezi počátečním bodem a hranicí pasti chudoby hraje důležitou roli při úniku z pasti chudoby. V popsaném modelu vláda ovlivňuje hranici pasti chudoby a pokud svou politikou přesune tuto hranici do počátečního bodu, výrazně zvýší jak pravděpodobnost úniku z pasti chudoby, tak vzrůst bohatství.
\end{abstract}

JEL Classification: E32, O41

Keywords: development trap, indeterminacy, sunspots, welfare

* Sergey.Slobodyan@cerge-ei.cz. (+420 2) 224005 211. This paper is based on the third essay of my Ph.D. thesis completed at Washington University in St. Louis, USA, and was partially written during a research visit to the Federal Reserve Bank in St. Louis. Financial support from both institutions is gratefully acknowledged. For helpful comments the author thanks William Barnett, Gaetano Antinolfi, James Bullard, John Duffy, Heinz Schaettler, Costas Azariadis, and participants of the CEF'99 Conference, $1^{\text {st }}$ CeNDEF Workshop, $8^{\text {th }}$ Annual SNDE Symposium, and World Congress of the Econometric Society. 


\section{Introduction}

"Sunspot equilibria" are "rational expectations equilibria in which purely extrinsic uncertainty affects equilibrium prices and allocations", see Woodford (1990). "Purely extrinsic uncertainty" denotes some random variable which has no effect on preferences, endowments, or technology. If this random variable and the resulting allocations and prices are stationary, one speaks about stationary sunspot equilibria, or SSE. In discrete time, one of the ways in which SSE are constructed is by randomization among different non-sunspot equilibria or deterministic trajectories converging to a steady state. This procedure can be performed when a non-sunspot steady state is locally indeterminate. Indeed, in a simple OLG economy with a constant supply of money, as in Azariadis (1981), a necessary condition for the existence of a particular kind of SSE is exactly the condition for the local indeterminacy of the non-sunspot rational expectations equilibrium (REE), see Woodford (1990). This connection between indeterminacy of a REE and the existence of some SSE (known as "Woodford's Conjecture") was established for a broad class of discrete time models, for example in Woodford (1986); Grandmont (1986); and Spear, Srivastava, and Woodford (1990).

The usual conclusion in the sunspot literature is that sunspots reduce welfare because of the agents' risk aversion. Following the sunspot variable results in a less smooth consumption path. On average, one should see a lower intertemporal welfare. However, if sunspots can lead to escape from an inferior steady state (poverty trap) as is posited in Slobodyan (2001), this conclusion does not necessarily hold. Escaping trajectories can have much higher welfare than those remaining in the poverty trap, especially if the escape happened 
early, thus increasing ex-post expected intertemporal welfare in the presence of sunspots. The model described in Slobodyan (2001) included two competing influences on the expected intertemporal welfare functional. One could expect a positive influence to prevail for the initial conditions, guaranteeing high escape probability. Conversely, a low escape probability might mean a negative ex-post contribution from self-fulfilling beliefs to the intertemporal welfare.

Two factors play a major role in determining the net result of the two effects. First is the difference between welfare accumulated along trajectories originating "just inside" of the trap and "just outside" of it. For example, if convergence to the steady state is fast and contemporary utility is significantly different in the steady states, then one would expect a rather large step between "just inside" and "just outside" trajectories. The other major factor is escape probability. When the initial point implies a high escape probability, the expected intertemporal welfare should be higher, all other parameters being equal.

The first major factor, the "step" in intertemporal welfare, is not large in the Slobodyan (2001) model for the simple reason that for realistic values of the increasing returns to scale, two eigenvalues with negative real parts are complex. The trajectory converging to the positive steady state does so in an oscillatory fashion. In particular, the trajectories that start just above the poverty trap boundary spend a long time eating up capital stock, behaving exactly like the trajectories in the trap. Accumulation of the capital which eventually leads to higher contemporary utility starts relatively late, when the discount factor $e^{-\rho t}$ is already significantly lower than one. Benefits of being out of the trap are diminished as a result. 
The second major factor, probability of escape, was extensively studied in Slobodyan (2001). There exists a band of initial conditions below the trap boundary, such that trajectories initiated in this band have a non-negligible probability of escape. This probability increases as the initial condition approaches the boundary. Therefore, only for initial conditions very close to the boundary is the effect of sunspot fluctuations expected to be positive on average. For the rest the result will be zero or negative.

The degree of risk aversion also contributes to the expected sign and magnitude of the sunspot's influence on welfare. A high degree of risk aversion might mean that the negative impact prevails even in the region where the probability of escape is reasonably high.

To obtain some insights into the relative strength of those competing influences as a function of model parameters, I performed numerical simulations of the SDE derived in Slobodyan (2001), and calculated the welfare along different stochastic trajectories. The main result is relatively pessimistic. Even though a non-negligible probability of escape exists for initial consumption levels 10 to 20 percent lower than the boundary value, ex-post expected welfare in this region is essentially the same as in the deterministic case. The negative effect of the sunspot fluctuations is close to zero. For initial conditions (capital and initial consumption) very close to the boundary, expected welfare in the sunspot case starts to dominate the deterministic one. It is impossible to quantify to what degree risk aversion influences welfare, because the expected welfare gain depends on it in a very complicated way.

Results of the current paper and of Slobodyan (2001) suggest that the distance from the poverty trap boundary to the initial condition point is of critical 
importance where the escape is concerned. I consider a model in which government has an influence on the exact location of the boundary. Implementing policy that moves the boundary to the initial point greatly increases both probability of escape and the expected welfare gain.

Section 2 of this paper gives numerical results for the effect of sunspot shocks on the ex-post expected intertemporal welfare in the model studied in Slobodyan (2001). Section 3 uses analytical results on escape probability to estimate expected welfare gains or losses. Section 4 slightly modifies a model in which the government can change the parameters of the tax regime. I consider whether government actions could change the location of the poverty trap boundary so that the economy becomes closer to the boundary. If this is possible, then the government could conduct a policy aimed at increasing the probability of escape under the influence of sunspot fluctuations. This opens up a channel of influence for the government, which is otherwise non-credible and unable to coordinate agents' beliefs on the trajectory converging to the welfare maximizing steady state.

\section{Influence of Sunspots on Welfare - Numeri- cal Results}

The model studied in this paper is the same as that used in Slobodyan (2001), and represents a version of the Benhabib and Farmer (1994) model. This deterministic continuous-time model with infinitely lived agents is characterized by increasing social returns to scale due to externality in the production function of which the agents are assumed to be unaware. There are two steady states; one with zero capital and zero consumption (the origin), the other with posi- 
tive levels of both capital and consumption. For some parameter values, both steady states are indeterminate, and the whole state space is separated into two regions of attraction of the steady state. The origin's region of attraction is a development trap. For the derivations, please refer to Slobodyan (2001).

The economy consists of a large number of identical consumers seeking to maximize

$$
\int_{0}^{\infty}\left(\frac{C^{1-\sigma}}{1-\sigma}-\frac{N^{1-\chi}}{1-\chi}\right) e^{-\rho t} d t
$$

subject to

$$
\dot{K}=(r-\delta) K+w N-C,
$$

where $C$ is consumption, $K$ capital, $N$ work effort, $r$ interest rate, and $w$ the wage rate. There are a large number of identical firms with the production function

$$
Y=K^{a} N^{b} \bar{K}^{\alpha-a} \bar{N}^{\beta-b},
$$

where $a+b=1, \alpha>a, \beta>b$, and $\bar{K}$ and $\bar{N}$ are economy-wide averages of $K$ and $N$ per firm, which are taken as given by every individual firm. The solution to the problem in log variables is given by the following system of equations, nearly equivalent to the one derived in the original Benhabib and Farmer (1994) model:

$$
\begin{aligned}
\dot{c} & =\left[\frac{a}{\sigma} \exp (w-v k+u c)-\frac{\delta+\rho}{\sigma}\right], \\
\dot{k} & =[\exp (w-v k+u c)-\exp (c-k)-\delta] .
\end{aligned}
$$


where $w, v$, and $u$ are given by

$$
\begin{aligned}
w & =-\frac{\beta \log (b)}{\beta+\chi-1}, \\
v & =\frac{\beta-(1-\alpha)(1-\chi)}{\beta+\chi-1}, \\
u & =\frac{\sigma \beta}{\beta+\chi-1} .
\end{aligned}
$$

After the changes of variables given below,

$$
\begin{aligned}
& x=\exp (w-v k+u c), \\
& y=\exp (c-k),
\end{aligned}
$$

the system transforms into

$$
\begin{aligned}
& \dot{x}=x\left[\left(\frac{a}{\sigma} u-v\right) x+v y+v \delta-u \frac{\delta+\rho}{\sigma}\right], \\
& \dot{y}=y\left[\left(\left(\frac{a}{\sigma}-1\right) x+y+\delta-\frac{\delta+\rho}{\sigma}\right)\right] .
\end{aligned}
$$

The steady states of (5) are

$$
\mathbf{A}=\left(\frac{\delta+\rho}{a}, \frac{\delta+\rho}{a}-\delta\right), \mathbf{B}=(0,0), \mathbf{C}=\left(0, \frac{\delta+\rho}{\sigma}-\delta\right), \text { and } \mathbf{D}=\left(\frac{u \frac{\delta+\rho}{\sigma}-v \delta}{\frac{a}{\sigma} u-v}, 0\right)
$$

If the following conditions hold,

$$
\begin{aligned}
\beta+\chi-1 & >0, \\
a\left(1+\frac{\rho}{\delta+\rho} \frac{\beta+\chi-1}{1-\chi}\right) & <\alpha<1, \\
(\sigma-1) \beta+(1-\alpha)(1-\chi) & >0,
\end{aligned}
$$

then the positive steady state $\mathbf{A}$ is indeterminate. Under those conditions, steady state $\mathbf{D}$ lies in the second quadrant and is of no interest, $\mathbf{B}$ is stable (in- 
determinate), and $\mathbf{C}$ is a saddle ${ }^{1}$. In addition, application of the Dulac criterion shows that (5) does not have limit cycles. The phase portrait of the model is presented in Figure 1. The whole first quadrant is divided into two regions of attraction $^{2}$. The only trajectories that diverge to infinity are those that start on the vertical axis above $\mathbf{C}$. The stable manifold of $\mathbf{C}$ serves as a separatrix between the regions of attraction. In logged consumption and capital, the phase portrait is given by Figure 2. All trajectories that start above the transformed stable manifold of $\mathbf{C}$ converge to the positive steady state $\mathbf{A}$. Trajectories with the initial conditions below it diverge to minus infinity. In the original $(C, K)$ variables (Figure 3 ), the phase portrait looks very similar to that of (5), the only difference being that now the separatrix of the two regions of attraction starts at the origin rather than on the vertical axis. The stable manifold approaches the origin as a ray of constant positive tangent, while any other trajectory of the system which approaches the origin behaves asymptotically as $C \sim K \exp (-\rho t)$. The distance between the stable manifold and any such trajectory expressed as a percentage of actual consumption level grows exponentially over time. The trivial solution of (5) - the origin - corresponds to a poverty trap, or imploding economy. To estimate numerically welfare gains or losses under the influence of sunspot fluctuations considered in Slobodyan (2001), I use a numerical scheme similar to the one used in that work (see Appendix D of Slobodyan (2001)).

\footnotetext{
${ }^{1}$ Steady states $\mathbf{B}$ and $\mathbf{C}$ both represent trajectories with different asymptotic behavior that diverge to $(-\infty,-\infty)$ in the $(c, k)$ space. The change of variables collapses infinity points from the lower half of the $(c, k)$ space onto the vertical half-axis in the $(x, y)$ space. Trajectories with different asymptotic behavior at minus infinity are mapped onto different points at the axis.

${ }^{2}$ There were previous attempts to obtain the region of stability of the positive steady state in this model; see, for example, Russell and Zecevic (1998) for the Lyapunov function approach. The approach used here is much broader, as it enables me to study the global dynamics of the model instead of the compact neighborhood of the steady state, as in the reference.
} 
Figure 1: Phase portrait of the transformed system in $(\mathrm{x}, \mathrm{y})$ variables

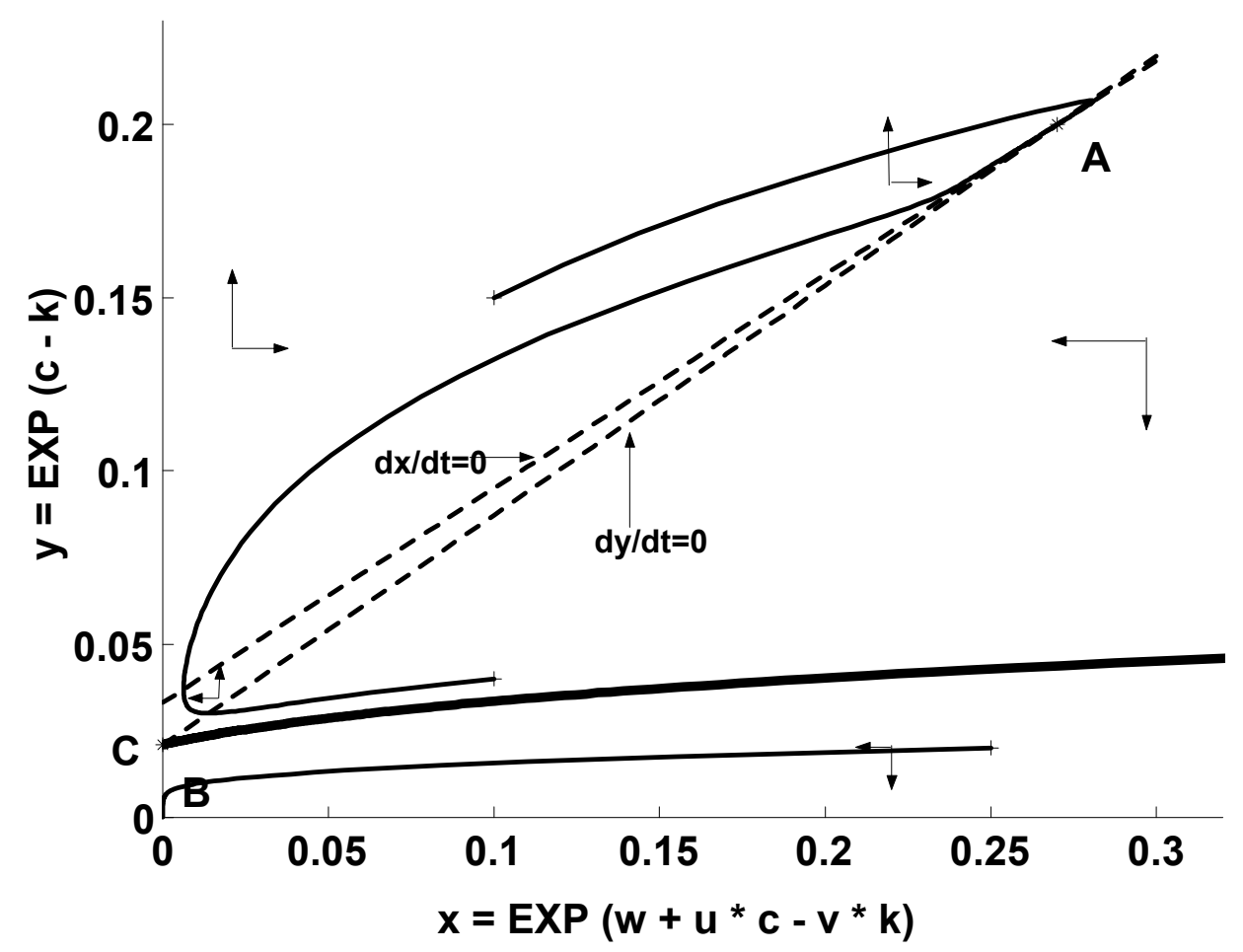

Writing the value of intertemporal welfare as a differential equation with initial value $0, \mathrm{I}$ arrive at the following:

$$
\begin{aligned}
d c & =\left[\frac{a}{\sigma} \exp (w-v k+u c)-\frac{\delta+\rho}{\sigma}\right] d t+\widetilde{\sigma} d W_{t}, \\
d k & =[\exp (w-v k+u c)-\exp (c-k)-\delta] d t, \\
d V & =e^{-\rho t}\left[\frac{\exp (c(1-\sigma))}{1-\sigma}-\frac{\exp (n(c, k)(1-\chi))}{(1-\chi)}\right] d t
\end{aligned}
$$

The system is three-dimensional, and there is an explicit dependence on time in the third equation. An explicit dependence of labor effort $n$ on the consumption and capital can be derived from first-order conditions of the model and substituted here. The numerical scheme used in Slobodyan (2001) needs only one 
Figure 2: Phase portrait in log capital and log consumption

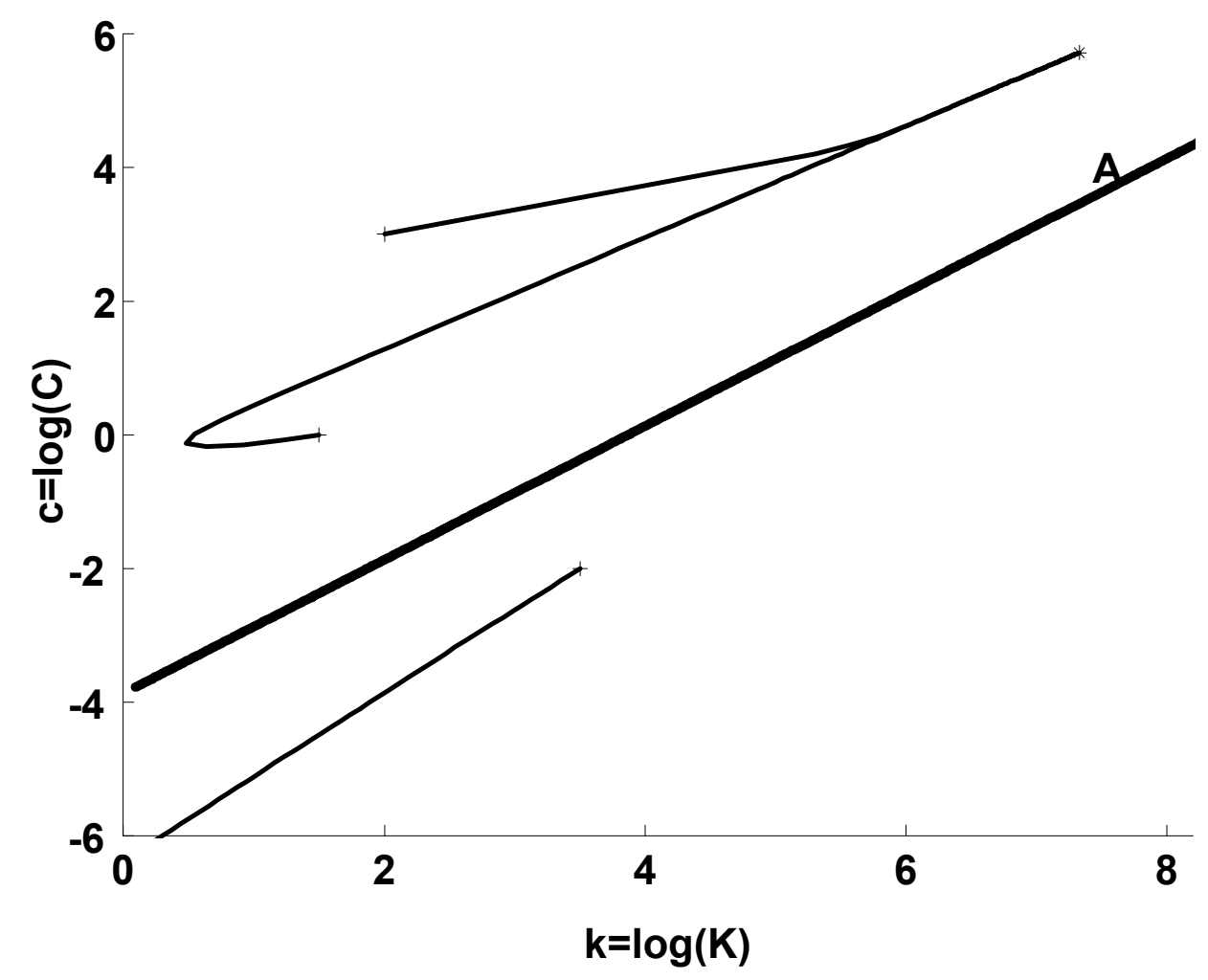

modification because of explicit dependence on time, $L^{0} f=\frac{\partial f}{d t}+b f^{\prime}+\frac{1}{2} \sigma^{2} f^{\prime \prime}$. I ran batches of 100 trajectories starting from initial points $\left(c_{g}(k)-d, k\right)$ where $c_{g}(k)$ is the value of log consumption on the trap boundary and $d=0.01 \ldots 0.20$. To decrease the time needed to run simulations I increased the discount rate for all models from 0.02 to 0.06 . Numerical simulations were run up to $t=100$. Time step $\Delta=0.1$ was used for all simulations. It was assumed that sunspot noise stops after the sample path consumption exceeds the boundary value by 0.01, therefore reducing escape probabilities. As explained above, the welfare accumulated along the trajectory that starts "just in" the trap is not very dif- 
Figure 3: Dynamics of the system in original, nonlogged variables

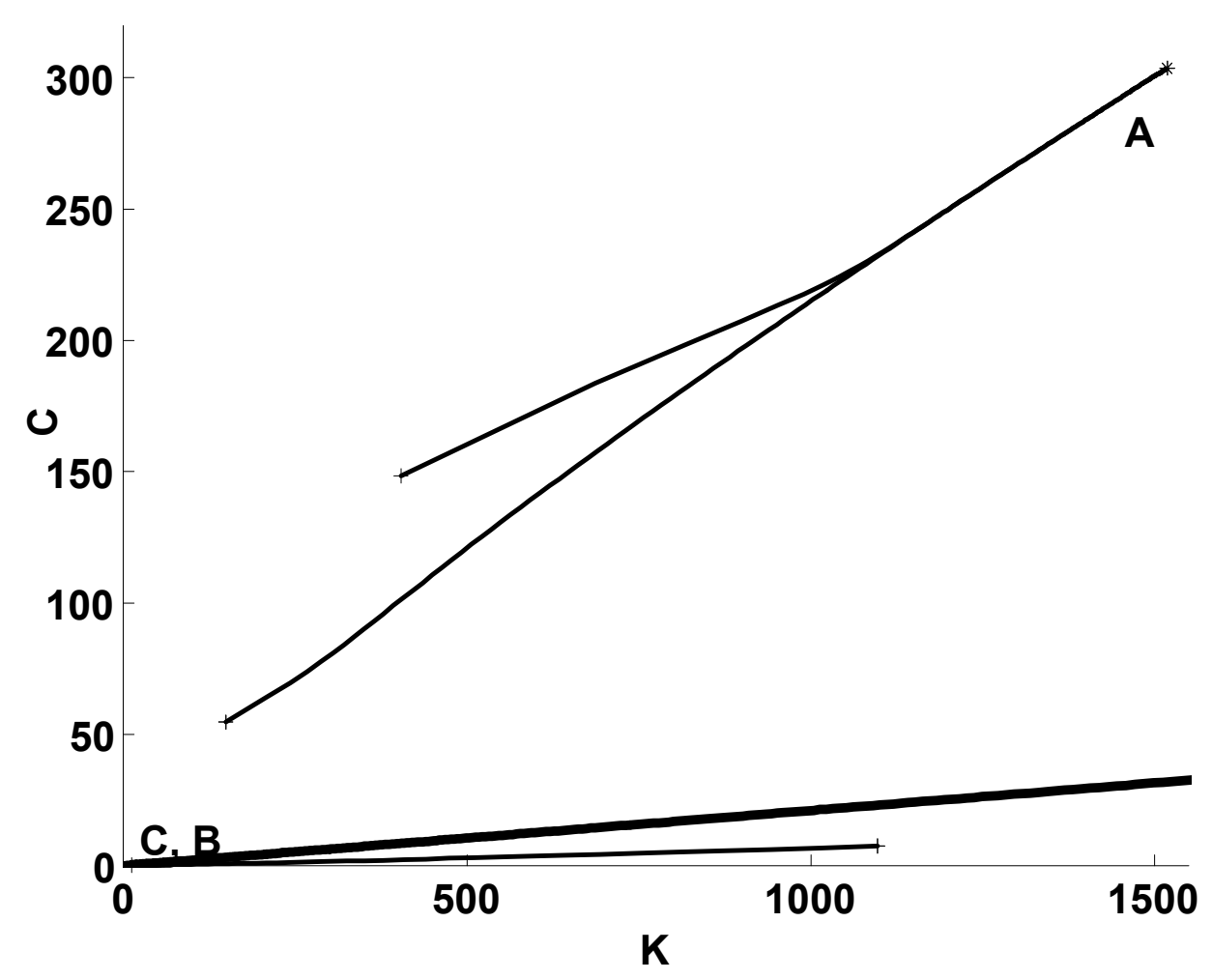

ferent from the welfare for the "just outside" trajectory. Requesting an extra 0.01 over the boundary allowed me to make this difference larger. Welfare levels for deterministic trajectories with the same initial conditions were calculated and used as reference values.

The results can be presented in two ways. One is to plot the average welfare gain (loss) as a function of initial $c$ and $k$. This plot facilitates comparisons with the analytical results obtained in the next section. Another way to look at the welfare gain (loss) is to derive the value of initial consumption that produces the same welfare in the deterministic case, without the sunspot fluctuations. 
Figure 4: Average welfare gain (loss) as a function of the distance to the trap boundary, Model 1

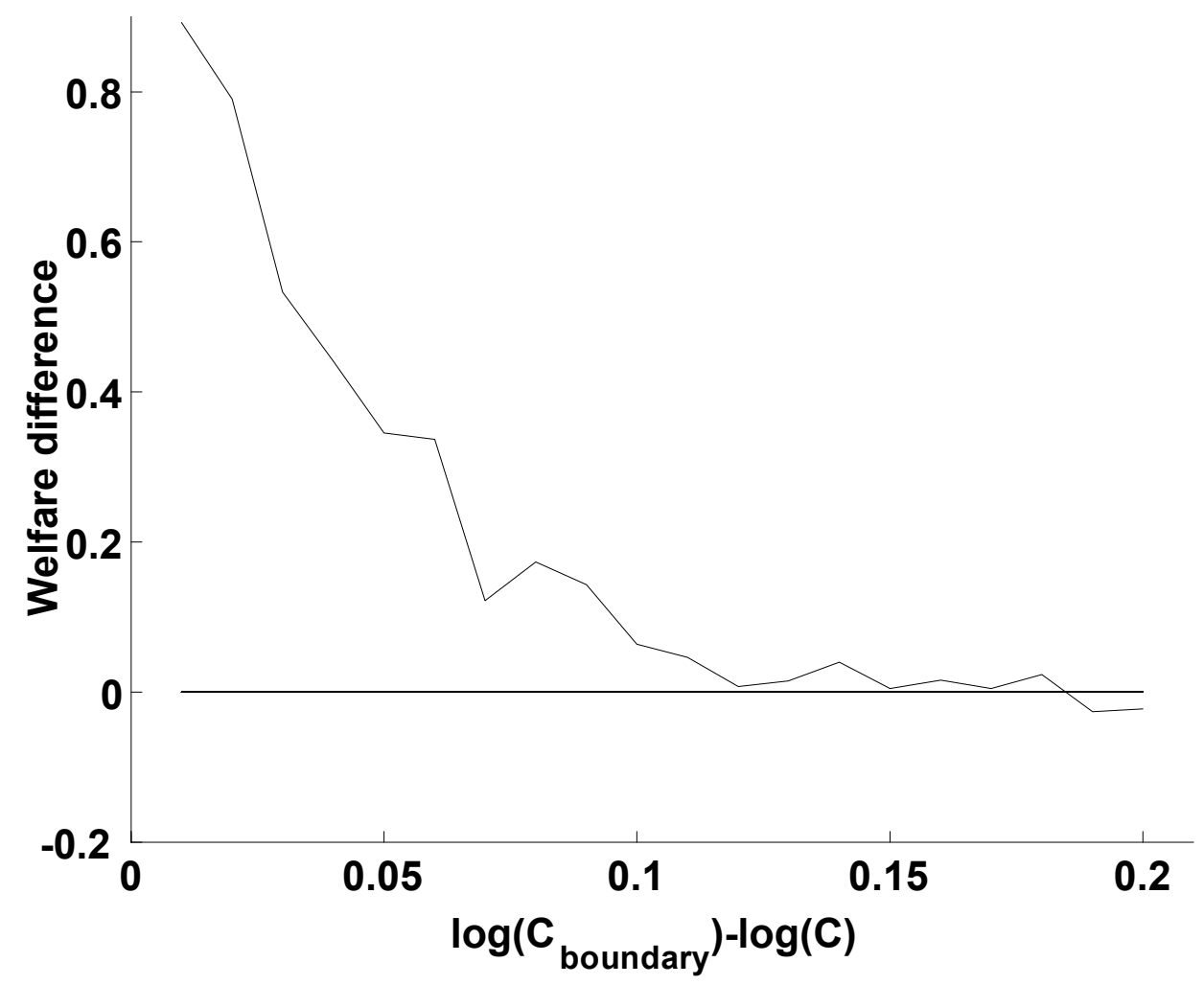

Figure 4 plots the difference between average welfare achieved under sunspot fluctuations and the value accumulated without fluctuations, but with the same initial conditions. As in Slobodyan (2001), there is no observable dependence on the initial level of capital $k$. Therefore, I aggregated the results for different initial $k$ and the same initial distance to the boundary. Surprisingly, I was unable to find a region where sunspots significantly lower the welfare. Even for an initial distance $d$ of about 0.20 (initial consumption approximately $20 \%$ lower than the boundary value) where the probability of escape is about $0.5 \%$, 
the welfare is essentially the same. The welfare cost of sunspot fluctuations far from the boundary is essentially zero. Yet when $d$ reduces to 0.10 or less, there is a noticeable increase in the average welfare gain. Translating this gain into initial consumption, which under deterministic conditions yields the same welfare, gives a $2.8 \%$ positive difference at peak value.

Figure 5: Welfare gain (loss) measured as additional consumption needed to generate the same welfare in the deterministic case, Model 1

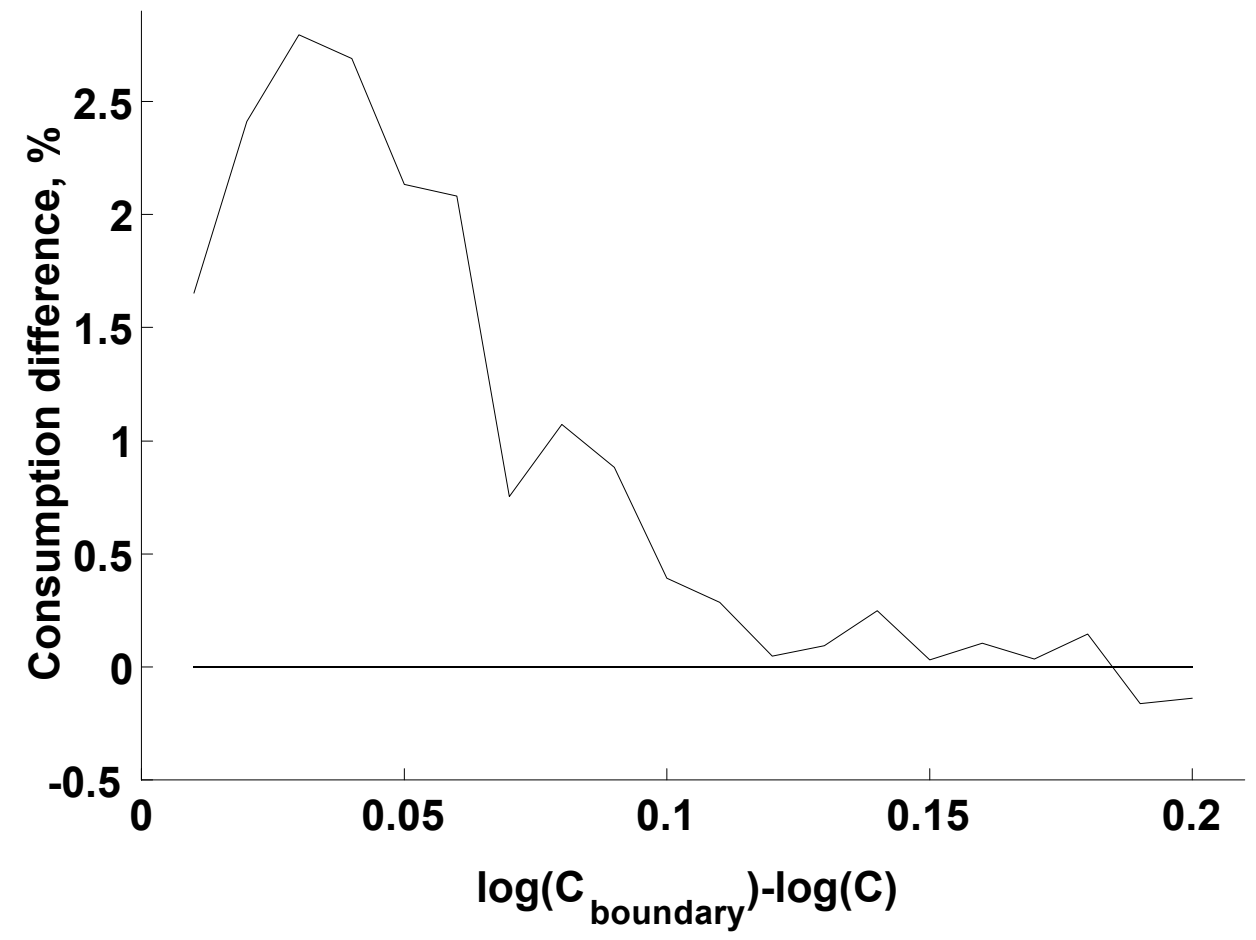

The certainty equivalent consumption gain peaks at $d=0.03$ rather than very close to the boundary. The reason for this is as follows. Suppose that the welfare difference between the "just in" and "just out" trajectories, which differ by $d=0.01$ in their initial conditions, is given by $\Delta$. Assume that two 
trajectories in the trap with the same difference in initial conditions, $d=0.01$, have a welfare difference of approximately $0.2 \Delta$. Then for a trajectory in the trap whose initial conditions imply a probability of escape at $50 \%$, one should expect a welfare gain of approximately $0.5 \Delta$, equivalent to approximately a $2.5 \%$ increase in the initial consumption. On the other hand, a trajectory that starts essentially at the boundary with probability of escape close to 1 cannot have the welfare gain more than $\Delta$, meaning that at most a $1 \%$ increase in the certainty equivalent consumption will be achieved.

Figure 6: Average welfare gain (loss) as a function of the distance to the trap boundary, Model 2

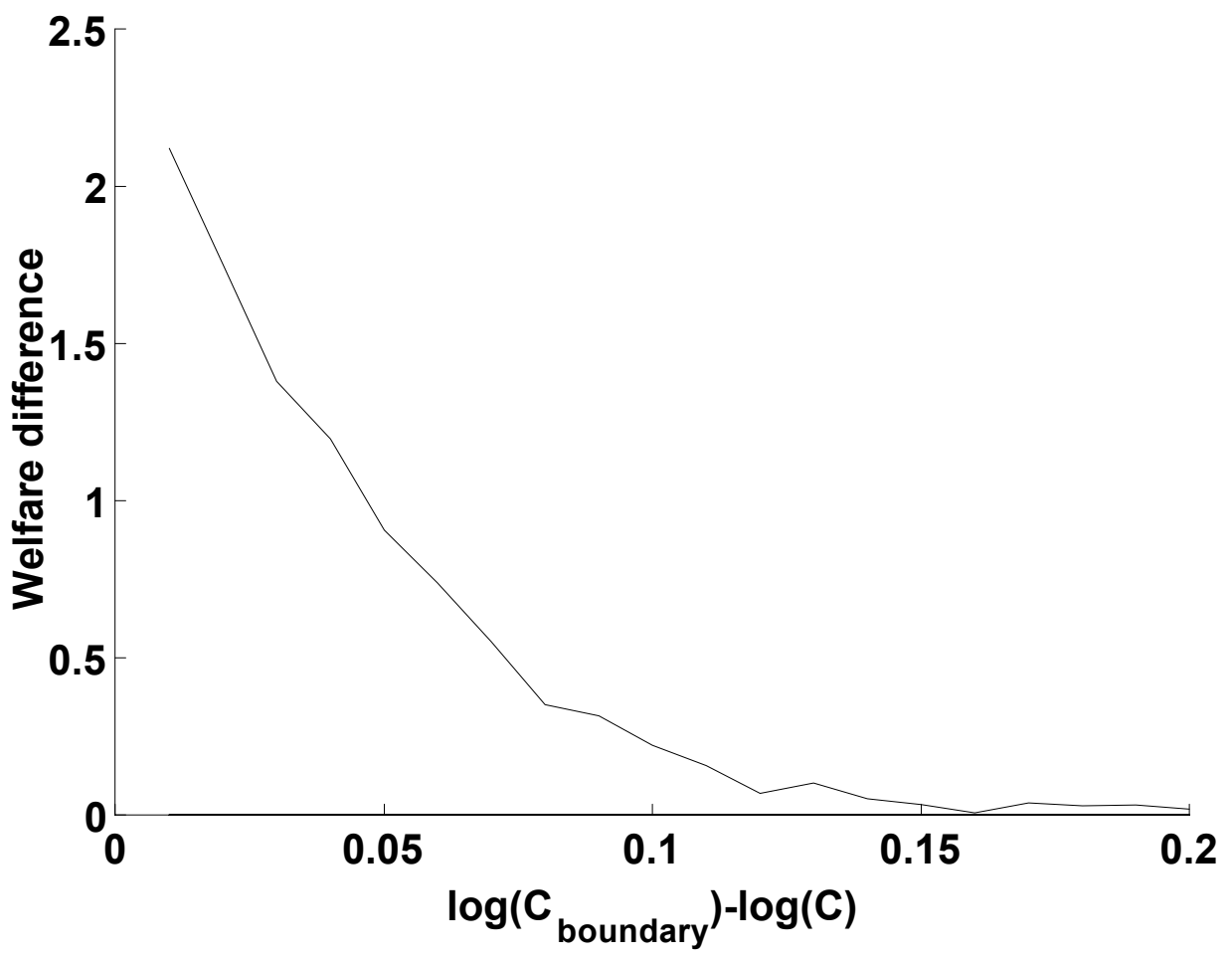

Figures 6 and 7 present the results for a model in which $\sigma=0.9$, denoted 
Figure 7: Welfare gain (loss) measured as additional consumption needed to generate the same welfare in the deterministic case, Model 2

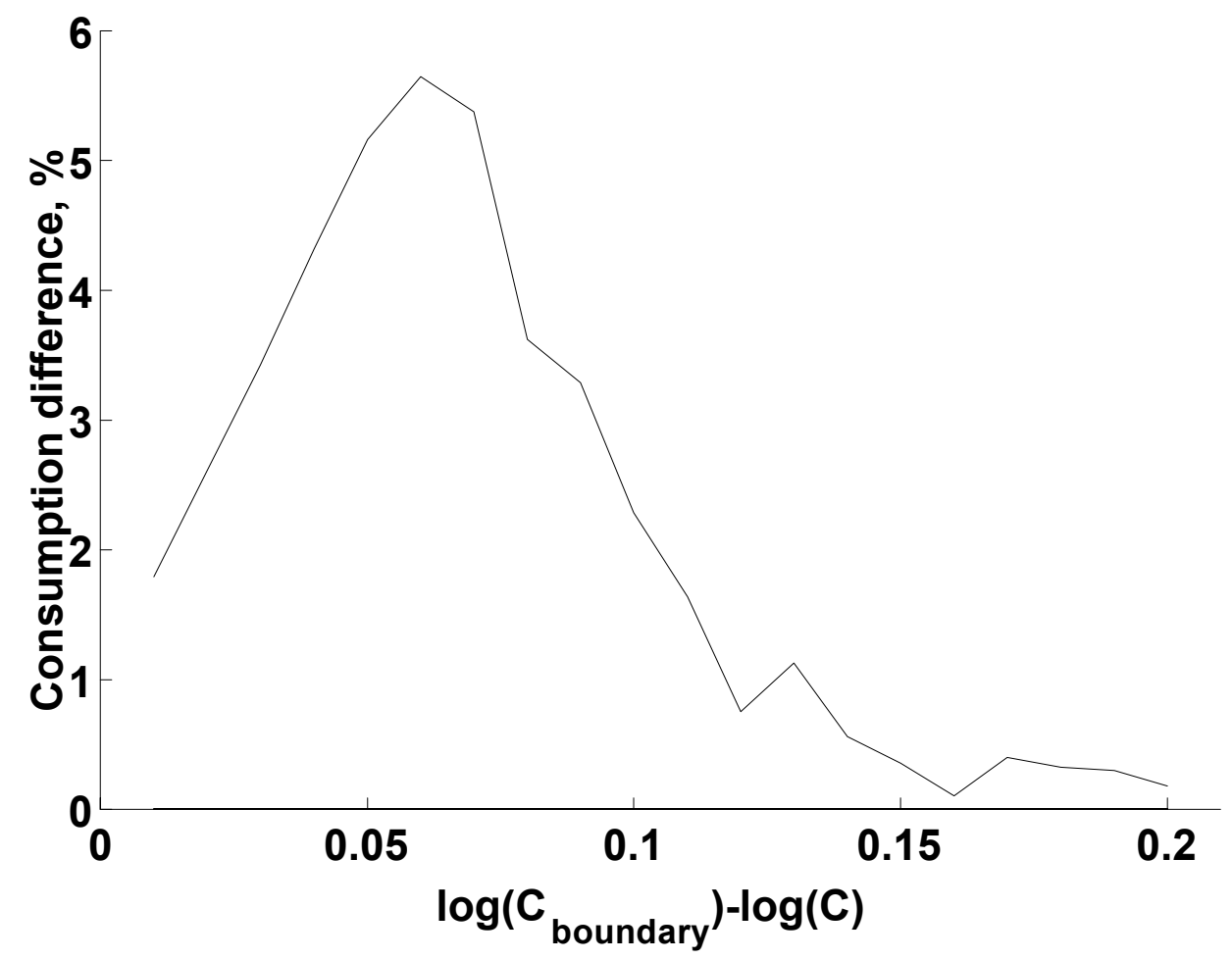

Model 2. Additionally, the level of increased returns to scale wis reduced to $\beta=1.5$ and $\alpha=0.5$ versus $\beta=1.67$ and $\alpha=0.83$ for the previous model. The remainder of the model's parameters is the same in Model 1 and Model 2. The results are very similar to those of Model 1. However, the peak in the certainty equivalent consumption gains is achieved farther from the boundary (at $d=0.06$ ), the peak itself is much higher at $5.8 \%$, and there is no region with an average welfare loss because of sunspots. All three features occur because of the large increase in intertemporal welfare once the trap boundary is crossed, as is clear from Figure 8. Expected benefits of even rare escapes from the trap 
are huge in this case.

Figure 8: Intertemporal welfare as function of the distance to the trap boundary, no sunspots, Model 2

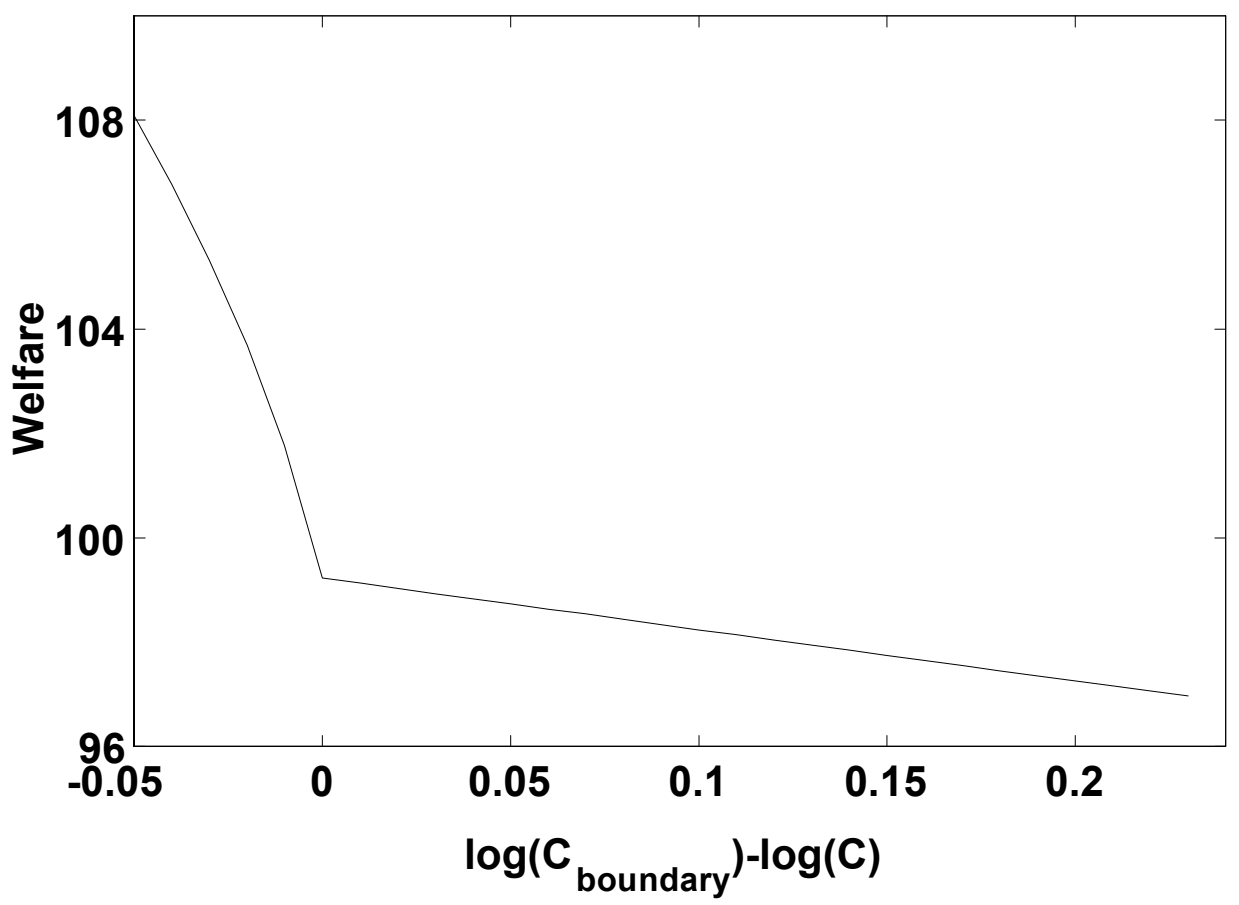

Similar simulations were performed for $\sigma$ as low as 0.5 . The following table summarizes the parameter values of the models presented here. Parameter values not mentioned in the table are the same as in Models 1 and 2 .

Note that the degree of increasing returns to scale is not constant for Models 1 through 6 . It is impossible to find $\alpha$ and $\beta$ such that for $\sigma$ ranging from 0.5 to 0.99 the positive steady state remains indeterminate. For example, $\alpha=0.83$, $\beta=1.66$ and $\sigma=0.90$ imply an explosive positive steady state. As was discussed in Slobodyan (2001), for the model used here the explosive positive steady state 


$\begin{array}{ccccc}\text { Model } & \alpha & \beta & \sigma & \widetilde{\sigma} \\ 1 & 0.83 & 1.66 & 0.99 & 0.024 \\ 2 & 0.50 & 1.50 & 0.90 & 0.026 \\ 3 & 0.50 & 1.50 & 0.80 & 0.026 \\ 4 & 0.50 & 1.50 & 0.70 & 0.021 \\ 5 & 0.50 & 1.50 & 0.60 & 0.0117 \\ 6 & 5 / 12 & 4 / 3 & 0.50 & 0.015\end{array}$

Table 1: Summary of the models used

means that no trajectory stays finite outside of the development trap. Note also that the magnitude of self-fulfilling belief noise does not stay constant. For each model this magnitude was calibrated to generate a standard deviation of the $\log$ consumption equal to $14 \%$ for fluctuations outside of the trap. This magnitude depends on the strength with which the drift term in equation (7) pushes consumption back to its steady state value, and is probably a complicated function of the model parameters ${ }^{3}$.

Certainty equivalent consumption gains for Models 3 through 6 are presented in Figures 9-12. Consumption gain as high as 6.5\% is achieved. Even for large distances from boundary $d$ there is no significantly negative effect of sunspots on welfare. It is possible that I observe what is called a "bunching effect" in Christiano and Harrison (1999): "The increasing returns means that by bunching hard work, consumption can be increased on average without raising the average level of employment" 4 . The fact that certainty equivalent consumption gain is almost everywhere positive means that the "bunching effect" dominates

\footnotetext{
${ }^{3}$ This magnitude should depend on the Lyapunov exponent of the stochastic flow around the positive steady state. Calculating the exponents is outside of the scope of this paper.

${ }^{4}$ This reference uses a discrete time version of the model used here. "Bunching hard work" for a trajectory that never leaves the trap means wandering closer to the boundary earlier rather than later.
} 
Figure 9: Welfare gain (loss) measured as additional consumption needed to generate the same welfare in the deterministic case, Model 3

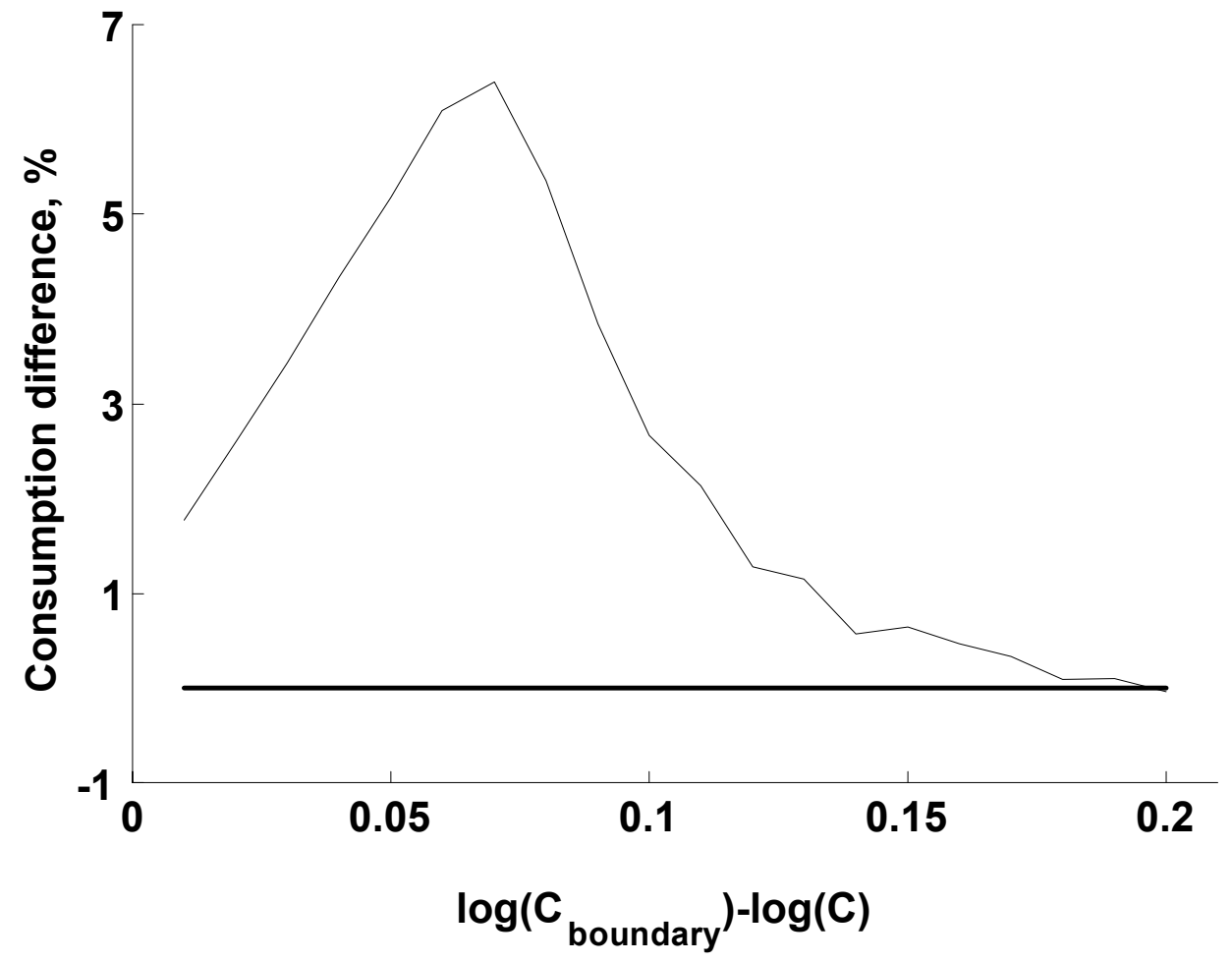

the negative influence of the convex utility function, and yet both those effects are very small. To demonstrate the smallness of the influence of sunspots on welfare in the region where escape probability is negligible, I plot the calculated average welfare gain together with $95 \%$ confidence bands. The plot is presented in Figure 13. Even for batches of 1500, confidence band for the welfare gain includes zero in the region where probability of escape is very low ${ }^{5}$.

Finally, I would like to compare the welfare gain from sunspot fluctuations with some estimates of the welfare cost of business cycles. In Lucas (1987)

\footnotetext{
${ }^{5}$ For this particular model, less than $0.5 \%$ of trajectories escape if $d>0.10$.
} 
Figure 10: Welfare gain (loss) measured as additional consumption needed to generate the same welfare in the deterministic case, Model 4

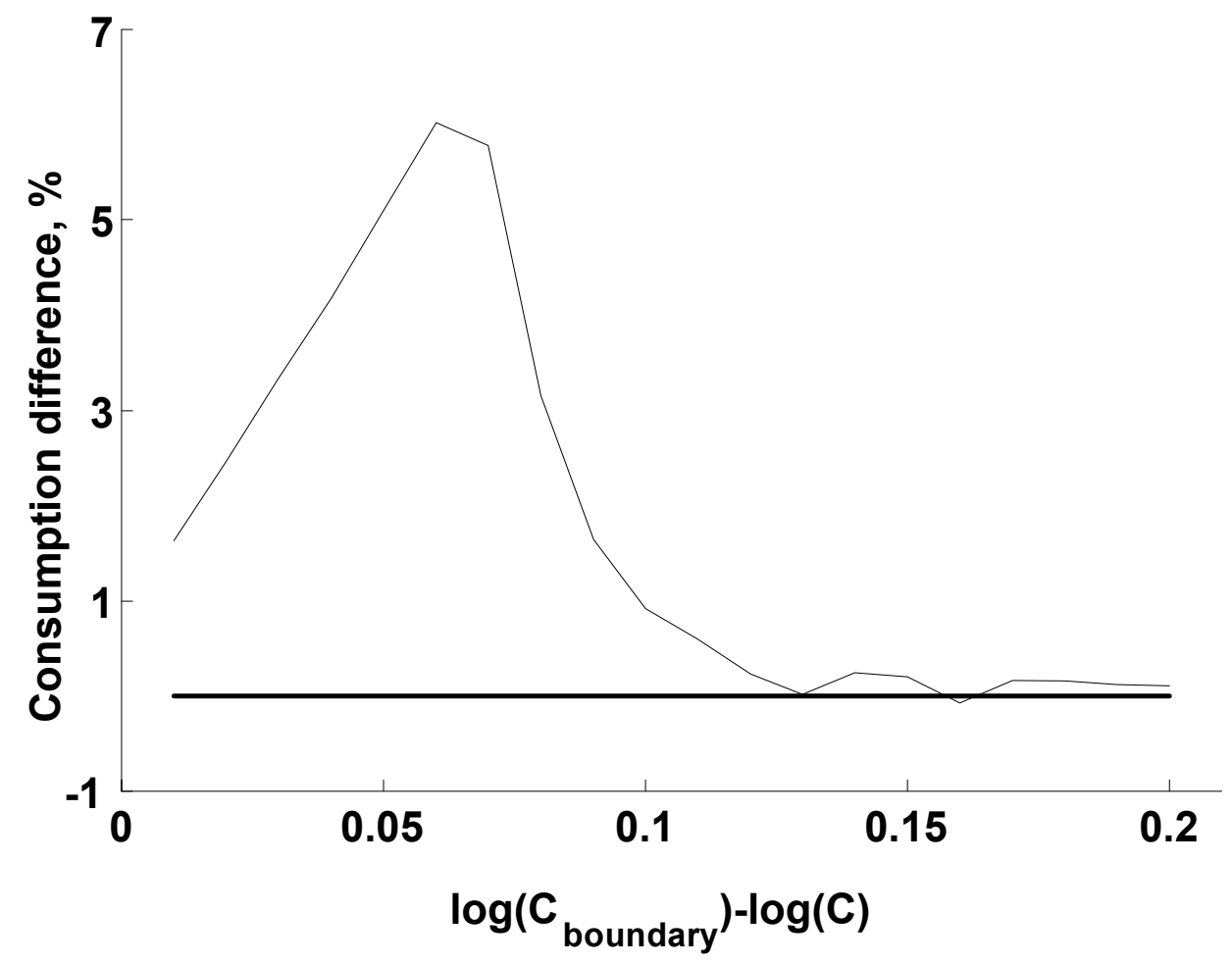

and Imrohoroglu (1989) this cost was estimated to be very small: a representative consumer would give up from $0.17 \%$ to $1.3 \%$ of consumption in every period to live in an environment without business cycles. For non-standard recursive utility Dolmas (1998) obtains much larger welfare costs, as much as $23 \%$ in the extreme case and $2-5 \%$ of consumption for a moderate degree of risk aversion. The certainty equivalent consumption gain achievable in the current model under sunspot fluctuations is of the same order of magnitude as the largest estimates of the welfare costs of business cycles ${ }^{6}$.

\footnotetext{
${ }^{6}$ I used historical performance of developing countries to calibrate the sunspot noise magnitude. Standard deviation of consumption in the developing countries was $1.5-3$ times larger
} 
Figure 11: Welfare gain (loss) measured as additional consumption needed to generate the same welfare in the deterministic case, Model 5

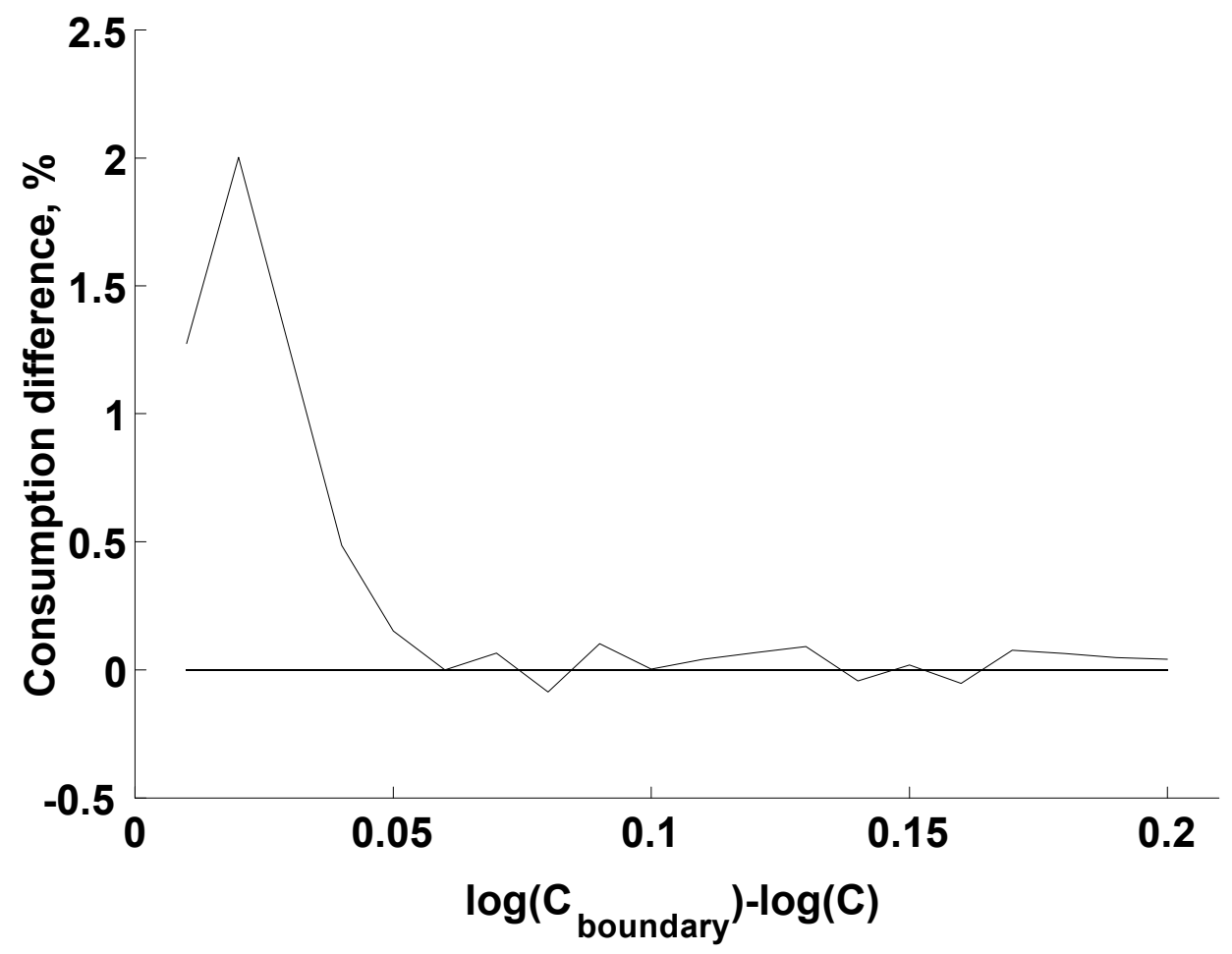

\section{Analytical Estimates of the Welfare Gain (Loss)}

Empirical results presented in the previous section demonstrate that there is almost no influence of sunspots on intertemporal welfare if the trajectory does not leave the trap. This result allows me to construct an approximation of the expected welfare gain caused by the sunspot fluctuations.

Fix the initial level of capital at $k_{0}$. Suppose the trajectory starts at $\left(k_{0}, c_{0}\right)$, where $c_{g}-c_{0}=d$ and $c_{g}\left(k_{0}\right)$ denotes the value of initial consumption on the than in the developed ones. If Lucas and Imrohoglu used developing countries data for their calculations, welfare costs of the business cycles would be larger. 
Figure 12: Welfare gain (loss) measured as additional consumption needed to generate the same welfare in the deterministic case, Model 6

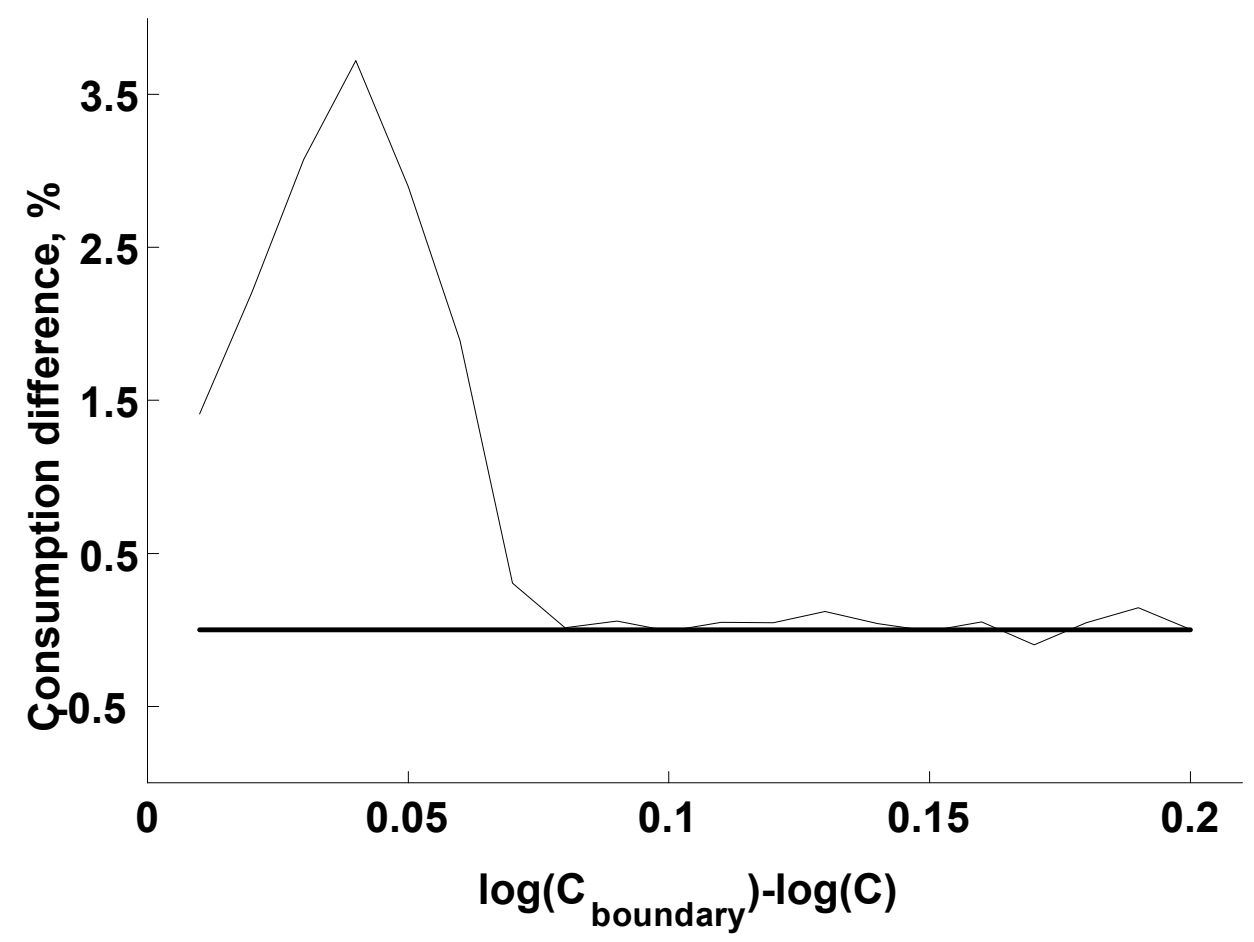

stable manifold (the trap boundary). Without sunspots a trajectory with initial conditions $\left(k_{0}, c_{0}\right)$ will accumulate intertemporal welfare $V\left(k_{0}, c_{0}\right)$. Make two other simplifying assumptions. First, assume that expected intertemporal welfare for the trajectories that do not leave the trap is given by $V\left(k_{0}, c_{0}\right)$. This assumption can be justified on empirical grounds, as Figures 4 and 6 demonstrate that the average welfare for such trajectories is very close to $V\left(k_{0}, c_{0}\right)$. Further assume that the trajectory which escapes the trap accumulates welfare equal to $V\left(k_{0}, c_{g}\right)+\Delta=V_{g}+\Delta$. This is a very crude approximation, because in general the welfare depends on the time of escape, $T_{d}$. Using the two 
Figure 13: Average welfare gain (loss) under the sunspot fluctuations with confidence bands, Model 4

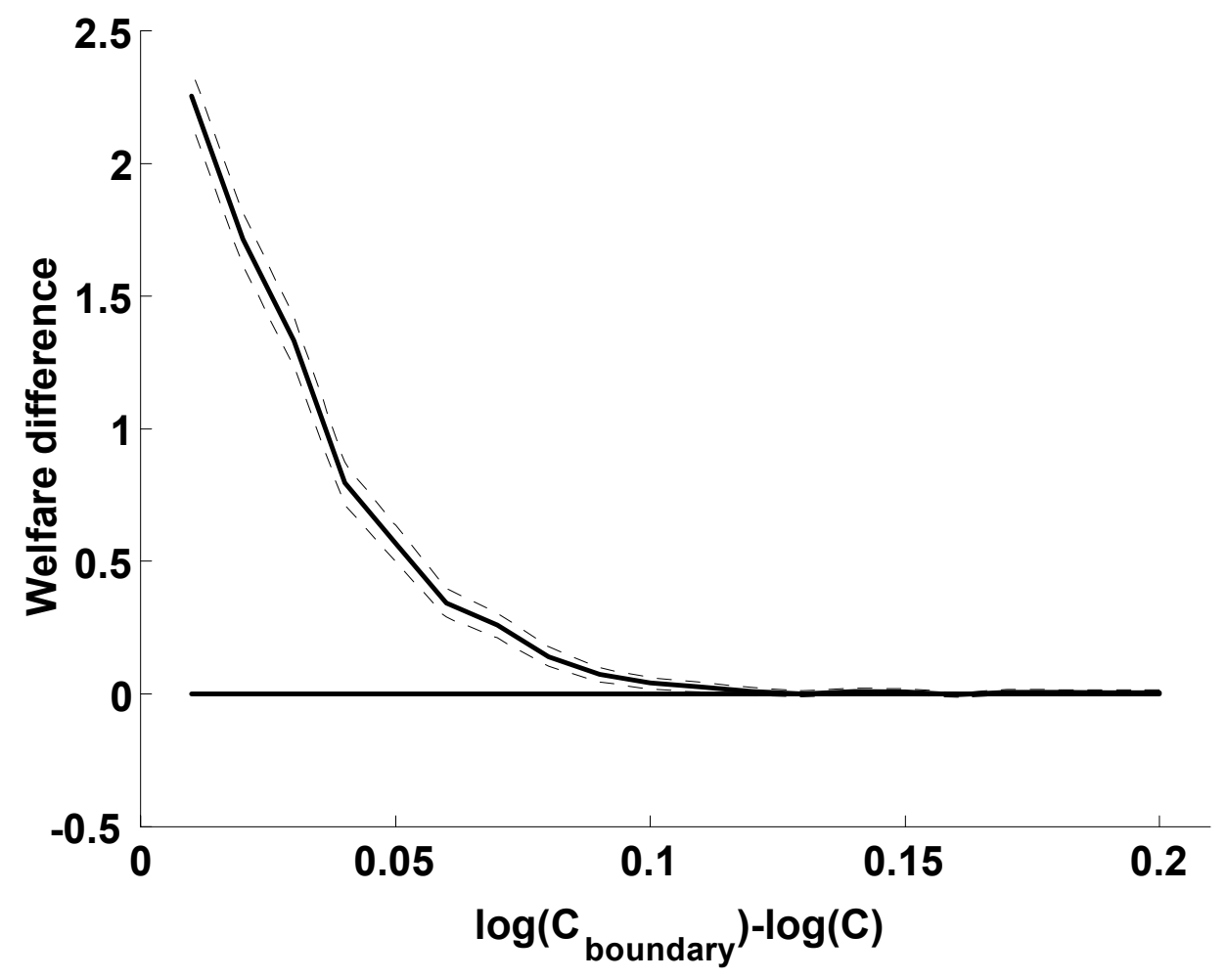

assumptions, write the expected welfare under sunspots, $E\left[V\left(k_{0}, c_{0}\right) \mid \widetilde{\sigma}\right]$, as

$$
E\left[V\left(k_{0}, c_{0}\right) \mid \widetilde{\sigma}\right]=P\left(T_{d+\epsilon}<\infty\right)\left(V_{g}+\Delta\right)+\left(1-P\left(T_{d+\epsilon}<\infty\right)\right) V\left(k_{0}, c_{0}\right) .
$$

Notice that I use $T_{d+\epsilon}$ instead of $T_{d}$, because the trajectory escapes (the sunspot variable stops) only after reaching $(c-k)_{g}+\epsilon$ in numerical simulations. Figure 10 demonstrates that $V\left(k_{0}, c_{0}\right)$ is a linear function of the distance to the boundary, $V\left(k_{0}, c_{0}\right)=V_{g}-\lambda d$. Probability of escape, $P\left(T_{d+\epsilon}<\infty\right)$, was calculated in Slobodyan (2001) and is given in Eq. (21) in that paper,

$$
P\left[T_{d+\varepsilon}<\infty\right]=\exp \left[-2\left(\frac{\delta+\rho}{\sigma}-\delta\right) \frac{(d+\varepsilon)\left(1-e^{-d-\varepsilon}\right)}{\tilde{\sigma}^{2}}\right]
$$


Substitute $P\left(T_{d+\epsilon}<\infty\right)$ into (8) and subtract the value of the welfare without sunspots, $V\left(k_{0}, c_{0}\right)=V_{g}-\lambda d$, to obtain an estimate of the expected welfare gain,

$$
E\left[V\left(k_{0}, c_{0}\right) \mid \widetilde{\sigma}\right]-V\left(k_{0}, c_{0}\right)=(\Delta+\lambda d) P\left(T_{d+\epsilon}<\infty\right) .
$$

Note that the expected gain is proportional to the probability of escape and is increasing in a nearly linearly fashion in $\Delta^{7}$. One should expect, then, that the logarithm of the average welfare gain is approximately inversely proportional to the square distance to the boundary, because $1-e^{-d-\varepsilon} \approx d+\varepsilon$ for small $d+\varepsilon$. A plot of the log expected gain versus $(d+\varepsilon)\left(1-e^{-(d+\varepsilon)}\right)$ is presented in Figure 14. Only those data points where the average welfare gain is significantly different from zero are plotted on the graph. The dependence is close to linear as implied by the formula above. As it is impossible to derive analytically the dependence of $\Delta$-welfare gain from escaping - on $\sigma$, I cannot say anything about the functional form of the dependence of the expected welfare gain on $\sigma$.

\section{Increasing the Probability of Escape}

It was demonstrated in the previous sections that if the economy is trapped and follows a sunspot random variable, getting the initial conditions as close to the trap boundary as possible is clearly beneficial. This increases the expected welfare gain from following the sunspot variable and the probability of escape from the trap. In the original Benhabib and Farmer (1994) paper the mechanism that could be used to adjust any of the model parameters is absent. The economy coordinates on some trajectory inside the trap and learns to believe

\footnotetext{
${ }^{7}$ For all the models studied here, $\Delta$ is much larger than $\lambda d$ in the area where the escape probability is not negligible, $\Delta \gg \lambda d$.
} 
Figure 14: Average welfare gain (loss) under the sunspot fluctuations, comparison with analytical results, Model 4

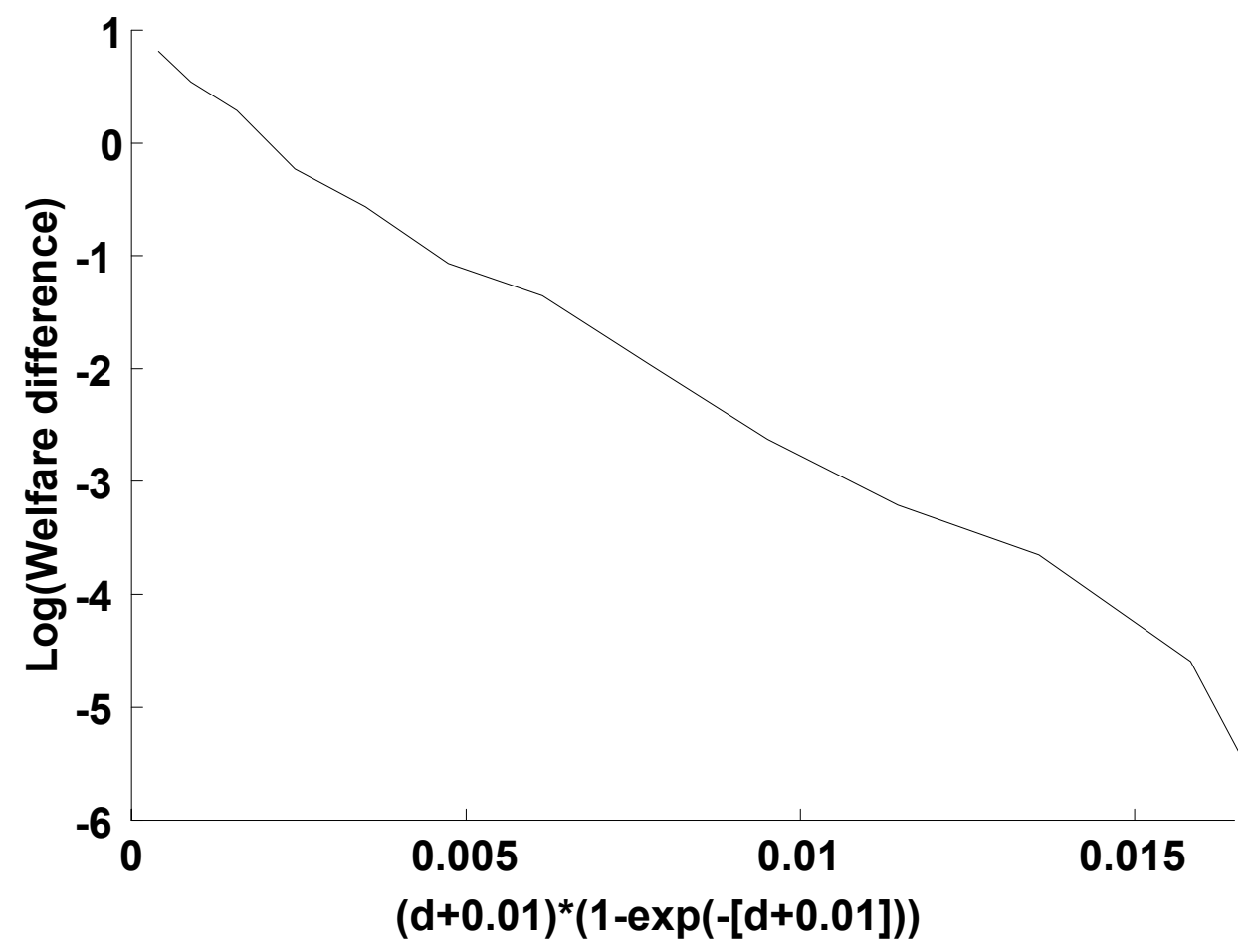

in a Wiener sunspot process. There is nothing capable of changing the initial condition and/or the poverty trap boundary.

In this final section I want to explore a model, based on Benhabib and Farmer (1994), which includes a government that can tax economic agents. My goal here is to look at different policy interventions, like a decrease in the total level of taxes collected, or changed progressiveness of the tax system. The situation will be very clear if some intervention achieves two objectives at the same time: decreasing the ordinate of the steady state $\mathbf{C}$ in Figure 1 and decrease the slope of the stable manifold at $\mathbf{C}$. If some simple intervention can 
achieve both objectives, then for any initial condition in the development trap the intervention lowers the distance between initial condition and the trap ${ }^{8}$. To predict the results of such an intervention it is necessary to assume that agents in the economy maintain the same level of consumption, thus leaving $y=C / K$ unchanged. The level of the work effort supplied by the agents jumps to the new level defined by the first order conditions. It is unclear what other assumptions could be maintained. For example, I could consider coordinated changes of consumption and labor effort that leave the instantaneous utility unchanged. However, the policy intervention will most likely change the level of the intertemporal utility that could be achieved by the economy in the steady state. It is unclear then on what grounds one could consider iso-utility changes.

The model used in this Section is a variant of Guo (1999). There is a continuum of identical households maximizing the utility

$$
\int_{0}^{\infty}\left(\log C-A \frac{N^{1-\chi}}{1-\chi}\right) e^{-\rho t} d t, A>0,
$$

where $C$ and $N$ are household consumption and working hours. Households own capital that is rented to firms, and the budget constraint is given by

$$
\dot{K}=\left(1-\tau_{k}\right)(r-\delta) K+\left(1-\tau_{n}\right) w N-C, K(0) \text { given, }
$$

with $r$ being the interest rate, $w$ the wage rate, and $K$ the household's capital stock. Tax rates are given by the following expressions:

$$
\begin{aligned}
& \tau_{k}=1-\eta_{k}\left(\frac{\bar{y}_{k}}{y_{k}}\right)^{\phi_{k}}, \eta_{k} \in[0,1], \phi_{k} \in[0,1), \\
& \tau_{n}=1-\eta_{n}\left(\frac{\bar{y}_{n}}{y_{n}}\right)^{\phi_{n}}, \eta_{n} \in[0,1], \phi_{n} \in[0,1),
\end{aligned}
$$

\footnotetext{
${ }^{8}$ This will be true for small $x$, but $x$ is very small for realistic values of $k$ inside the trap
} 
where $y_{n}=w N$ and $y_{k}=(r-\delta) K$ are the household's taxable labor and interest income. Tax code includes depreciation allowance. Parameters $\phi_{i}$ and $\eta_{i}, i=k, n$ determine the slope and the level of taxes. $\phi$ not equal to 0 means "progressive" tax, because in this case the marginal tax rate is higher than the average. In a departure from Guo (1999) where $\bar{y}_{k}$ and $\bar{y}_{n}$ were the steady state values of the of the taxable interest and wage income, in this paper they will represent economywide averages of respective incomes. The difference means that in a symmetric equilibrium where every household has the same amount of capital and supplies the same number of hours, tax rates will not depend on the current output. In the original paper, the symmetric equilibrium average tax rates were decreasing in the average level of output, thus generating countercyclical government spending. In the variant used here the average tax rate in the symmetric equilibrium does not depend on the business cycle stage, which more closely resembles the reality.

There is also a continuum of identical firms with the production function

$$
Y=K^{a} N^{b} \bar{K}^{\alpha-a} \bar{N}^{\beta-b},
$$

where $a+b=1, \alpha>a, \beta>b$, and $\bar{K}$ and $\bar{N}$ are economywide averages of $K$ and $N$ per firm, which are taken as given by every individual firm. From the profit maximization, the interest rate and the wage rate are given by

$$
\begin{aligned}
w N & =b Y, \\
r K & =a Y .
\end{aligned}
$$

The government balances its budget at every point in time. Therefore, there is no government debt in the model.

In a symmetric perfect foresight equilibrium every household has the same 
amount of capital, supplies the same number of hours, and every firm employs the same quantity of capital and labor. Using capital letters to denote aggregate values, I write the following current value Hamiltonian as

$$
H=\log C-A \frac{N^{1-\chi}}{1-\chi}+\mu\left(\eta_{k}\left(\frac{\bar{Y}_{k}}{Y_{k}}\right)^{\phi_{k}}(r-\delta) K+\eta_{n}\left(\frac{\bar{Y}_{n}}{Y_{n}}\right)^{\phi_{n}} w N-C\right) .
$$

Taking corresponding derivatives, one gets the necessary conditions:

$$
\begin{aligned}
\frac{1}{C} & =\mu, \\
A N^{-\chi} & =\left(1-\phi_{n}\right) \mu \eta_{n}\left(\frac{\bar{Y}_{n}}{Y_{n}}\right)^{\phi_{n}} w \\
\dot{\mu} & =\mu \rho-\mu\left(1-\phi_{k}\right) \eta_{k}\left(\frac{\bar{Y}_{k}}{Y_{k}}\right)^{\phi_{k}}(r-\delta), \\
\lim _{t \rightarrow \infty} e^{-\rho t} \frac{K}{C} & =0,
\end{aligned}
$$

together with the capital accumulation equation

$$
\dot{K}=\eta_{k}(r-\delta) k+\eta_{n} w N-C, K(0) \text { given }
$$

Substituting (19) into (20) and (21), recalling that by definition in the symmetric equilibrium $\bar{Y}_{n}=Y_{n}=w N, \bar{Y}_{k}=Y_{k}=(r-\delta) K$, and substituting in (16) and (17), one obtains the following set of equations:

$$
\begin{aligned}
A C N^{1-\chi} & =\left(1-\phi_{n}\right) \eta_{n} b Y, \\
\frac{\dot{C}}{C} & =\left(1-\phi_{k}\right) \eta_{k} \frac{a Y-\delta K}{K}-\rho, \\
\frac{\dot{K}}{K} & =\eta_{k} \frac{a Y-\delta K}{K}+\eta_{n} b \frac{Y}{K}-\frac{C}{K}, \\
Y & =K^{\alpha} N^{\beta}, \\
\lim _{t \rightarrow \infty} e^{-\rho t} \frac{K}{C} & =0 .
\end{aligned}
$$

Switching to $\operatorname{logs}, c=\log (C), k=\log (K), y=\log (Y)$, and using (24) and (27) to obtain $y$ as a function of $c$ and $k$, I arrive at the following 2-dimensional 
system of differential equations

$$
\begin{aligned}
\dot{c} & =\left(1-\phi_{k}\right) \eta_{k}(a \exp (w+u c-v k)-\delta-\rho), \\
\dot{k} & =\left(a \eta_{k}+b \eta_{n}\right) \exp (w+u c-v k)-\eta_{k} \delta-\exp (c-k),
\end{aligned}
$$

where

$$
\begin{aligned}
w & =\frac{\beta}{\beta+\chi-1}\left(\log (A)-\log \left(\eta_{n}\left(1-\phi_{n}\right)\right)-\log (b)\right), \\
v & =\frac{\beta-(1-\alpha)(1-\chi)}{\beta+\chi-1}, \\
u & =\frac{\beta}{\beta+\chi-1} .
\end{aligned}
$$

Finally, changing the coordinates to

$$
\begin{aligned}
& x=\exp (w-v k+u c), \\
& y=\exp (c-k),
\end{aligned}
$$

I get the system of equations presented below,

$$
\begin{aligned}
& \dot{x}=x\left\{\left[a u\left(1-\phi_{k}\right) \eta_{k}-v\left(a \eta_{k}+b \eta_{n}\right)\right] x+v y-u \rho-\left[u\left(1-\phi_{k}\right)-v\right] \eta_{k} \delta\right\}, \\
& \dot{y}=y\left\{\left[\left(1-\phi_{k}\right) \eta_{k}-\left(a \eta_{k}+b \eta_{n}\right)\right] x+y+\phi_{k} \eta_{k} \delta-\rho\right\} .
\end{aligned}
$$

By construction, $x$ and $y$ are nonnegative, therefore only the first quadrant of the $(x, y)$ space should be considered.

It is possible to carry on the same procedure as with the model used in accompanying paper and show that the current model's phase portrait is essentially the one presented in Figure 1. If $u>v$ then Jacobian at the positive steady state has positive determinant and indeterminacy is possible. To get a stable origin I need $\rho>\delta \eta_{k} \phi_{k}$. The latter condition also guarantees that the steady state $\mathbf{C}=\left(0, \rho-\delta \eta_{k} \phi_{k}\right)$ is located on the vertical half of the $y$ axis and that $\mathbf{C}$ is a saddle. The area beneath the stable manifold of $\mathbf{C}$ is the development trap exactly as in the previous model. 
As mentioned previously I should consider two possible influences of any policy intervention. One is the change in the "height" of the steady state $\mathbf{C}$, and another is the change in the initial slope of the stable manifold of $\mathbf{C}$. In order to make the calculations simpler assume that there is no difference between labor and capital in the tax code, i.e. $\eta_{k}=\eta_{n}=\eta$ and $\phi_{k}=\phi_{n}=\phi$. The two variables of interest are given by

$$
\begin{aligned}
y_{0} & =\rho-\delta \eta \phi \\
y_{1} & =\frac{(a \phi \eta+(1-a) \eta) y_{0}}{(u-v) \delta \eta+(u-v+1) y_{0}} .
\end{aligned}
$$

As mentioned previously, for realistic values of the capital (say, less than $e^{-1}$ times the value at the positive steady state) the value of consumption that puts the economy into the trap implies very low $x^{9}$. In the first approximation one can disregard the effect of the policy intervention on $y_{1}$ and concentrate on $y_{0}$ instead.

If $\eta=1, \phi=0$ then there are no taxes in this economy. The policy intervention that lowers the stable manifold of $\mathbf{C}$ is a shift to progressive taxation, $\phi>0$. In this case there still are no taxes in the symmetric equilibrium and the change is revenue neutral. On the other hand, if the economy initially had a flat tax code, $\eta<1, \phi=0$, then two interventions achieve the same goal increasing the progressiveness of the tax code and reducing the level of taxes by increasing $\eta$. Those two interventions work for any tax code such that it is not absolutely progressive $(\phi<1)$ and taxes in the symmetric equilibrium exist $(\eta<1)$.

\footnotetext{
${ }^{9}$ Variable $x$ is proportional to the interest rate $r$ in both the current model and the one used in the accompanying paper. Pessimistic initial consumption means low work effort and low productivity of capital, supressing interest rates.
} 
If $\rho<\delta$ then a very dramatic intervention becomes possible. When $y_{0}=$ $\rho-\delta \eta \phi=0$, the steady state $\mathbf{C}$ merges with the origin and moves to the lower half of the vertical axis if one further increases $\eta$ or $\phi$. The origin in this case loses stability and becomes a saddle. Figure 1 shows that in this case the development trap disappears and every trajectory converges to the positive steady state $\mathbf{A}$. However, for $\rho>\delta$ this is impossible.

Using the same approximation to the stochastic process solving (34) and calculating the probability of escape as in the previous paper, one gets

$$
P\left[T_{d}<\infty\right]=\exp \left[-2(\rho-\delta \eta \phi) \frac{d\left(1-e^{-d}\right)}{\widetilde{\sigma}^{2}}\right] .
$$

It is easy to see that any policy that reduces $d$ and $y_{0}$ increases the probability of escape from the trap.

Summary of the effects of policy interventions is given in the following claim.

Claim 1 Assume that the level of consumption does not discontinuously change through the policy intervention. Then the following policies lower the development trap boundary and increase the probability of escape:

i) increasing progressiveness of the tax code (increasing $\phi$ );

ii) reducing the symmetric equilibrium tax rate (increasing $\eta$ );

iii) combining i) and ii).

Moreover, if $\rho<\delta$ then moving to a very low tax rate $(\eta \approx 1)$ and very progressive tax code $(\phi \approx 1)$ eliminates the development trap altogether.

For completeness I will study the effect of changes in $\eta$ or $\phi$ on $y_{1}$. Taking the derivative of $y_{1}$ with respect to $\eta$ and simplifying, I get the following expression

$$
\begin{aligned}
& \frac{\partial y_{1}}{d \eta}=\frac{a \phi+1-a}{\left[(u-v) \delta \eta+(u-v+1) y_{0}\right]^{2}} \times \\
& \times\left[\delta \eta(u-v) \delta \eta \phi+(u-v+1) y_{0}^{2}\right]>0 .
\end{aligned}
$$


Therefore, the intervention that decreases $y_{0}$ also increases $y_{1}$. For large $x$ the effect of the policy intervention thus becomes ambiguous - it can increase or decrease the distance to the trap boundary.

The effect of changing $\phi$ on $y_{1}$ is ambiguous. The derivative is given by

$$
\begin{gathered}
\frac{\partial y_{1}}{d \phi}=\frac{\eta}{\left[(u-v) \delta \eta+(u-v+1) y_{0}\right]^{2}} \times \\
\times\left[a y_{0}\left((u-v) \delta \eta+(u-v+1) y_{0}\right)-(a \phi+1-a)(u-v) \delta^{2} \eta^{2}\right] .
\end{gathered}
$$

It is impossible to sign the derivative in the general case. Some limit cases can be studied, however.

Assume that $y_{0}=\rho-\delta \eta \phi=0$. In this case

$$
\frac{\partial y_{1}}{d \phi}=-\eta \frac{a \delta \eta(u-v) \delta \eta \phi+(1-a)(u-v) \delta^{2} \eta^{2}}{[(u-v) \delta \eta]^{2}}<0 .
$$

At the point where the steady state $\mathbf{C}$ merges with the origin $\frac{\partial y_{1}}{d \phi}$ is negative. By continuity $\frac{\partial y_{1}}{d \phi}$ is negative also in some neighborhood of the point $\left(\eta^{*}, \phi^{*}\right)$ where $\rho-\delta \eta^{*} \phi^{*}=0$. In this neighborhood a policy that increases the tax code progressiveness (raising $\phi$ ) decreases both the intercept and the slope of the stable manifold.

Consider now $\left.\frac{\partial y_{1}}{d \phi}\right|_{\phi=0}$. This derivative is proportional to

$$
a \rho^{2}(u-v+1)+a(u-v) \rho \delta \eta-(1-a)(u-v)(\delta \eta)^{2} .
$$

This is a quadratic equation in $\frac{\rho}{\delta \eta}$. For $\frac{\rho}{\delta \eta}=0,(38)$ is negative and therefore is negative in some neighborhood of this point. $\frac{\rho}{\delta \eta}$ is small when $\eta$ is large (low tax rate) and $\rho$ is low relative to $\delta$. However for $\rho \approx \delta$, which is a usual assumption in the literature, (38) is likely to be positive.

The above analysis demonstrates that second order effect of the policy directed to increased escape probability is likely to be negative. The only case 
where it is likely to be positive is when $y_{0}=\rho-\delta \eta \phi$ is very low and the development trap is small. As observed previously, for realistic values of the initial capital second order changes will be negligible because $x$ is very small.

\section{Conclusion}

In this paper I used numerical simulations of stochastic differential equations to study the influence of self-fulfilling beliefs driven fluctuations on the expected intertemporal welfare of a representative agent. I expected to see 2 major influences - a negative effect because of convexity of the utility function, and a positive one related to the significantly higher welfare achievable along the trajectories that escape from the poverty trap. I demonstrated that for the sunspot specification used both here and in the accompanying paper, Slobodyan (2001), there is no discernible negative effect on the average welfare if the fluctuations do not lead to escape from the poverty trap. The positive effect related to the positive contribution from escaped trajectories can be rather large. If I want to find a deterministic trajectory producing the same welfare as the average quantity generated by a batch of sunspot-driven paths starting from the same initial conditions, then I need to start the deterministic trajectory with consumption level up to $7 \%$ higher. For the model used here sunspot fluctuations are unambiguously positive. They either leave the welfare unchanged on average, or increase it rather significantly if there is significant probability of escape from the poverty trap because of sunspots. The effect depends on the initial difference between consumption and its boundary value.

As mentioned above, sunspots are not very beneficial in the current model. The main reason for this is the fact that welfare difference between the trajectory 
immediately inside the trap and the one immediately outside is not large. The behavior along the two paths remains similar for a long period of time, and agents just eat up the remaining capital. I can imagine 2 possible ways in which this behavior can be changed. The first approach is to shift to stochastic processes that are not continuous. For example, one could model the sunspot as a Poisson process - continuous time stochastic process with jumps ${ }^{10}$. In this case a successful jump far outside from the trap will put the system on a very beneficial trajectory which is impossible under my specification. Another approach is to look at the models of the development trap where the behavior is different and a trajectory after the escape changes the behavior dramatically. For example, in Gali (1995) it is possible to have 3 steady states, with "low" and "high" ones being saddles, and the "middle" one a sink ${ }^{11}$. The region of stability of the "middle" steady state is the development trap in this model. The region is bordered by two stable manifolds, one of them converging to the "low" steady state, and another to the "high" one. If the escape from the trap occurs when the sunspot-driven trajectory hits a stable manifold, then the trajectory making escape towards the "high" steady state immediately starts accumulating extra capital and welfare.

Finally, I looked into the possible role of a government in the model allowing indeterminate poverty trap. Both current and the accompanying papers clearly demonstrated how important the distance between the initial condition and the boundary of the poverty trap is. If the initial condition is relatively hard

\footnotetext{
${ }^{10}$ This approach is close to the one used in the literature. Both Drugeon and Wigniolle (1996) and Shigoka (1994) use continuous time stochastic process with jumps to model the sunspot variable. In the discrete time literature, the sunspot variable has jumps by definition.

${ }^{11}$ This case is presented on Figure 4 of the reference.
} 
to move (it might be determined by habit formation or cultural norms), then moving the poverty trap boundary instead can help the economy. In a version of the model studied here that allows taxation of the income, reducing the tax rate or increasing progressiveness of the tax code lowers the trap boundary for realistic initial conditions, thus increasing the probability of belief driven escape and expected welfare gain from sunspot fluctuations.

\section{References}

Azariadis, C. (1981): "Self-Fulfilling Prophecies," Journal of Economic Theory, $25,380-396$.

Benhabib, J., and R. E. Farmer (1994): "Indeterminacy and Increasing Returns," Journal of Economic Theory, 63, 97-112.

Christiano, L. J., and S. G. Harrison (1999): "Chaos, Sunspots and Automatic Stabilizers," Journal of Monetary Economics, 44, 3-31.

Dolmas, J. (1998): "Risk Preferences and the Welfare Cost of Business Cycles," Review of Economic Dynamics, 1, 646-676.

Drugeon, J.-P., and B. Wigniolle (1996): "Continuous-Time Sunspot Equilibria and Dynamics in a Model of Growth," Journal of Economic Theory, $69,24-52$.

Gali, J. (1995): "Product Diversity, Endogenous Markups, and Development Traps," Journal of Monetary Economics, 36, 39-63.

Grandmont, J.-M. (1986): "Stabilizing Competitive Business Cycles," Journal of Economic Theory, 40, 57-76. 
Guo, J.-T. (1999): "Multiple Equilibria and Progressive Taxation of Labor Income," Economics Letters, 65, 97-103.

Imrohoroglu, A. (1989): "Cost of Business Cycles with Indivisibilities and Liquidity Constraints," Journal of Political Economy, 97, 1364-1383.

LuCAS, R. E. (1987): Models of Business Cycles. Basil Blackwell, New York.

Russell, T., And A. Zecevic (1998): "Lyapunov Stability, Regions of Attraction, and Indeterminate Growth Paths," Economics Letters, 58, 319-324.

ShigokA, T. (1994): "A Note on Woodford's Conjecture: Constructing Stationary Sunspot Equilibria in a Continuous Time Model," Journal of Economic Theory, 64, 531-540.

Slobodyan, S. (2001): "Sunspot Fluctuations: A Way Out of a Development Trap?," CERGE-EI Working Paper 175.

Spear, S. E., S. Srivastava, and M. Woodford (1990): "Indeterminacy of Stationary Equilibrium in Stochastic Overlapping Generations Models," Journal of Economic Growth, 50, 265-284.

Woodford, M. (1986): "Stationary Sunspot Equilibria in a Finance Constrained Economy," Journal of Economic Theory, 40, 128-137.

(1990): "Learning to Believe in Sunspots," Econometrica, 58, 277-307. 